\title{
Business Intelligence in College: A Teaching Case with Real Life Puzzles
}

\author{
Wanda Presthus and Bendik Bygstad \\ The Norwegian School of IT, Oslo, Norway
}

prewan@nith.no; bygben@nith.no

\section{Executive Summary}

Modern Business Intelligence (BI) is about the process of turning data into actionable information, using an assortment of tools, techniques, and applications. Although BI, or its predecessor Decision Support Systems (DSS), has been applied in the industry for about half a century, it has only recently been taught in business schools. In the report "State of Business Intelligence in Academia 2010" Wixom and Ariyachandra found that the discipline faces many challenges in its way from practice to academia. For the lecturer, challenges include access to data sets and finding suitable cases, as well as providing realistic and meaningful examples. For the students, on the other hand, the problem is that $\mathrm{BI}$ is ripe with concepts and acronyms and appears too theoretical and abstract.

In this study we report from an introductory Bachelor course in Business Intelligence and reflect on the learning process. Our focus is how to make Business Intelligence education more fun and motivating for the students, while at the same time providing the BI lecturer with some examples from real life. We conducted a small action research study in a university college with a class of third year e-business students. Drawing on principles from Problem-Based Learning and PuzzleBased Learning, we employed a framework of real life puzzles. Each puzzle consists of real life problems, real life data, and real life solutions.

Our main contribution is that the real life puzzle approach is a powerful method to teach Business Intelligence concepts and processes. We argue that the similarities between the BI process and the puzzle solving process prepare the students for Business Intelligence learning, in an indirect way. Through the gradual realization on how these puzzles work, the students are able to connect the logical structures of puzzles with the rational way of BI queries. This prepares the students for Business Intelligence learning, and also for practice in working life. This insight should be of interest to any lecturer of BI.

Keywords: Business Intelligence, business school, real life puzzles, teaching case

Material published as part of this publication, either on-line or in print, is copyrighted by the Informing Science Institute. Permission to make digital or paper copy of part or all of these works for personal or classroom use is granted without fee provided that the copies are not made or distributed for profit or commercial advantage AND that copies 1 ) bear this notice in full and 2) give the full citation on the first page. It is permissible to abstract these works so long as credit is given. To copy in all other cases or to republish or to post on a server or to redistribute to lists requires specific permission and payment of a fee. Contact Publisher@InformingScience.org to request redistribution permission.

\section{Introduction}

The main aim of Business Intelligence (BI) is to support decisions for an organization, by providing access to existing data (Davenport, 2010; Li, 2005). Today, BI is regarded as an umbrella term combining architectures, tools, databases, applications, and methodologies. Its major objective is to provide 
reliable data to decision makers (Turban, Sharda, \& Delen, 2011).

Although the BI discipline originated in the business world, BI is now becoming a popular topic in higher education (Wixom \& Ariyachandra, 2011). However, in their comprehensive report "State of BI" Wixom and Ariyachandra (2011) found that BI faces many hurdles in its way from practice to academia. They received responses from 173 universities, and the results revealed that the top challenges for the lecturer are access to data sets and finding suitable cases. Other concerns are providing realistic, meaningful experiences. Accordingly, the students require more and better real-world software and real-world data sets. The students typically states, "It would help to be shown real-world cases or see how companies use BI in every-day operations" and "I find $B I$ interesting, but in my class it's really boring and uninteresting because all of the articles we read rehash the same ideas and solutions over and over again" (Wixom \& Ariyachandra, 2011, p. 13).

Thus, the students' needs are exactly what the lecturer find challenging to provide. How can this problem be mitigated? Unfortunately, it is not enough to assure the students that BI discipline is both interesting and important in a business context. For the average BI student, business analysis may be years away while the boring class is highly present. Therefore, teacher enthusiasm is not enough to motivate the students, and in this situation a more short-term strategy is needed.

Drawing on Moursund (2007) our point of departure is that having fun is an important experience in human life and an undervalued feature of education. We do not argue that the teacher needs to be a stand-up comedian; however, thinking back most people will remember something from childhood when they could have fun and learn something at the same time. Often, working with puzzles is associated with having fun (Michaelewicz \& Michaelewicz, 2007). Puzzles are amusing because they are based on a mystery or real world problem; you know that there is one correct answer and that there is rational reasoning behind the solution. We will illustrate that all these aspects are present in BI problem solving through our research question: How can real life puzzles contribute to improved learning in BI?

We proceed as follows: after reviewing the relevant literature and drawing on insights from Puzzle-Based Learning and Problem-Based Learning, we suggest a framework for real life puzzles in BI. Our method approach is a small action research project in which we conducted one cycle based on our framework with four real life puzzles given to the BI students at the Bachelor level. Then we discuss our findings, the viability and limitations of Puzzle-Based teaching. Our contribution is mainly practical: we wish to provide BI teachers in higher education with a framework for an engaging way of teaching.

\section{Related Literature}

In this section, we present the basic concepts of $\mathrm{BI}$, and highlight some challenges for the lecturer of BI in academia. Then we review the concepts of Problem-Based Learning and Puzzle-Based Learning, which result in our framework.

\section{Concepts of Business Intelligence}

The concept of BI emerged for the very first time in 1958 in an IBM journal article by Luhn titled “A Business Intelligence System”, which described principles for analyzing textual data automatically. In Power's chronicle of Decision Support Systems (DSS) (2007), BI is regarded as an offspring from DSS in the late 1960s and 1970s, along with siblings such as data warehouses, Executive Information Systems, and OLAP which all came in the late 1980s and early 1990s. Modern Business Intelligence comprises various tools, applications, processes, databases and architectures for all levels of an organization by providing access to data (Turban et al., 2011). The major components of BI are illustrated by Turban, Aronson, Liang, and Sharda (2007) in Figure 1 
and will be described in some detail to elaborate on the concepts which are discussed in this article.

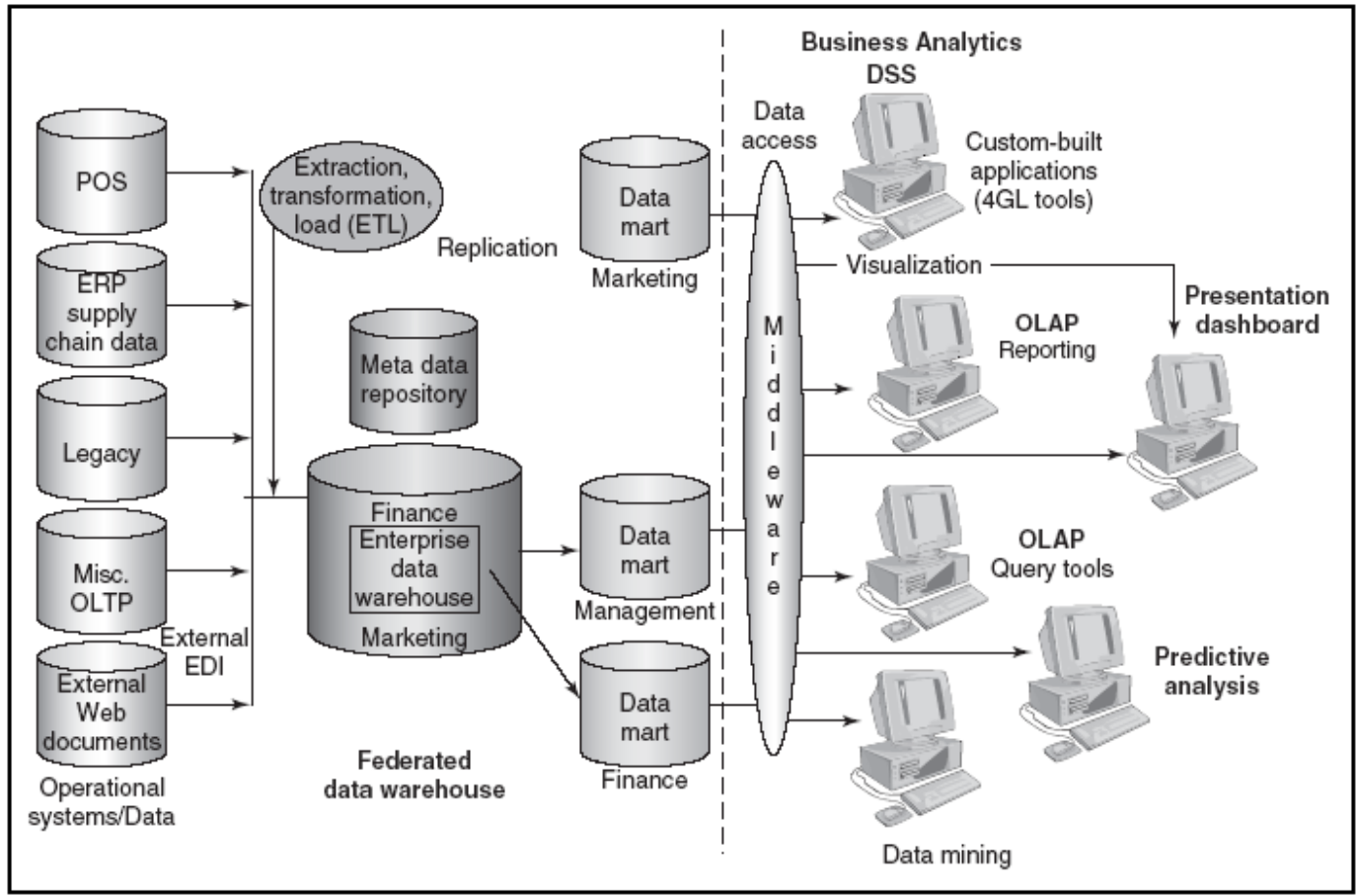

Figure 1: The major components of Business Intelligence (Turban et al., 2007, p. 201)

Various sources of data are found on the very left of Figure 1. One example of Point of Sale (POS) is data from scanning retail products. ETL is an abbreviation for Extraction, Transformation and Load and is a key concept in any data warehouse, enhancing data quality. A data warehouse is “.... a collection of data in support of management's decision making..." (Connolly \& Begg, 2010, p. 1147). The BI tool-kit on the right side of the dotted line in Figure 1 comprises online analytical processing (OLAP) reporting and data mining. The new trends in today's BI are text- and web mining, which can serve as foundations for sentiment analysis, a technique used to identify customer's positive or negative opinions towards a product (Turban et al., 2011).

The aim of BI is to turn a company's data into actionable information. The BI process consists of four steps: gathering data, turning data into information, making decisions, and finally taking action (Turban et al., 2011). Research has shown that many companies do not make it through the whole BI process, and tend to halt after having achieved information, but not taking action (Davenport, Harris, De Long, \& Jacobsen, 2001; Howson, 2008; Overby, Bharadwaj, \& Sambamurthy, 2006).

\section{Business Intelligence in Academia}

Business Intelligence is now being taught at a growing number of universities and colleges around the world (Wixom \& Ariyachandra, 2011), and research on teaching BI is beginning to emerge, not only in computer science programs, but also in business schools (Edgington, 2011; Mrdalj, 2011).

In 2011, The Teradata University, a teaching resource for Business Intelligence and Data Warehousing, supported 2560 faculty members belonging to 1262 colleges and universities located in 85 countries (Wixom et al., 2011). 
Publications on teaching BI include Fang and Tuladhar (2006) who described the concepts of data warehousing and OLAP and their experiences of successfully teaching this to technology students. Building on Fang and Tuladhar, Mrdalj (2007) argued that it is important to combine theory and practice, as well as use real-world examples in the lectures. This approach "...made this class exciting what otherwise used to be dry presentations of the analytical data mining techniques" (Mrdalj, 2007, p. 38). Moreover, Mrdalj advised using a large variety of data samples, but also pointed out that preparing for such a course was extremely time-consuming for the lecturer. Addressing the challenge of "access to BI software”, identified by Wixom et al. (2011), Mrdalj recently published an article suggesting cloud computing (Mrdalj, 2011). One of his major concerns is that BI will fail as a course for Master students of Business Administration due to technical issues. Mrdalj concludes that cloud computing may indeed contribute to better teaching of BI as this outsourcing will enable the students to focus on the business value of BI.

New courses for business schools are being created, focusing on various components of BI, such as text mining (Edgington, 2011). Similar to Mrdalj, Edgington's new college discipline focuses on analysis and validity in addition to the use of the technology.

\section{Problem-Based Learning and Puzzle-Based Learning}

Problem-Based Learning (Savery, 2006) is an instructional approach that encourages creative thinking on real life problems with open-ended solutions. The teacher facilitates the students' learning and reflection while the students work in groups. Problem-Based Learning has more focus on the learning process for the students and less focus on the answers reached.

While Problem-Based Learning allows for several outcomes, a puzzle will always have one fixed solution. In their paper, Michaelewicz and Michaelewicz (2007) reported how Puzzle-Based Learning can be used to teach engineering students to solve problems by thinking more creatively. There are multiple reasons behind most students' enthusiasm for Puzzle-Based Learning. Puzzles are educational, thought-provoking, and make problem-solving entertaining. The conclusion of the puzzle can be transferred to solving real-world problems (Michaelewicz \& Michaelewicz, 2007).

Well known examples of puzzles are crosswords, jigsaw, and solitaire (Moursund, 2007). Some puzzles can only be solved by thinking out-of-the-box, meaning that we need to think differently to solve the problem. An illustration is the "Gordian Knot", which is impossible to untie (consequently, by thinking out-of-the-box you chop it off with a hatchet). According to Moursund, thinking out-of-the-box is important today because the students will need to solve global challenges.

We believe that the principle of Problem-Based Learning (real life problems) and the PuzzleBased Learning principles (thinking out-of-the-box) are relevant for making BI education more fun and motivating for the students. Our approach was to take a real life situation and make a puzzle from it. This framework is described in the next section.

\section{Real Life Puzzles as Framework}

Based on the review in the previous section, there are three aspects associated with ProblemBased Learning and Puzzle-Based Learning in a BI context that we find significant.

Real life problems: According to Problem-Based Learning, a problem should be ill-structured and come from the real world, which motivates the students to find a solution (Savery, 2006). We agree that the problem should come from the real world, but we do not believe that it needs to be unstructured. Rather, based on previous research (Davenport et al., 2001; Overby et al., 2006), we 
believe that teaching BI should indeed train the students to pay attention to data analysis, but also on how to make decisions based on these data in order to solve the problem.

Real life data: Second, BI is often characterized by large volumes of real life data, for example data from point-of-sale (POS) scanning in retail stores (Davenport et al., 2001). This fact represents a unique opportunity of puzzle investigation in huge volumes of data. Such data can be found on web pages, by asking companies, or taking a documented case from the real world and recreating a puzzle of it.

Real life solutions: Lastly, Puzzle-Based Learning emphasizes that the fun aspect of puzzles is determined by the fact that there is only one correct solution. The correct solution can be surprising but completely logical according the data material. Business Intelligence has a logical approach, and its main issue is about making decisions based on data instead of previous experience or intuition (Turban et al., 2011). Although data in real life may not always provide a clear pattern, even by means of the plethora of modern BI tools, we believe that in a learning situation there should only be one revealing answer.

These three real life aspects of problems-data-solutions will be used in our analysis and discussion.

\section{Method}

Our article reports on a teaching case, conducted as a small Action Research project. Action Research is a recognized approach in several fields (Reason \& Bradbury, 2007) including Information Systems research (Baskerville, 1999). Recently, there has been an increasing interest in using Action Research in higher education (Norton, 2009).

The teaching case was carried out at the Norwegian School of IT during the autumn semester of 2010. The class counted 28 e-business students, attending the ten ECTS Business Intelligence course in the fifth semester of the Bachelor of Information Technology. The main learning objectives of the BI course were as follows: master key concepts, acquire knowledge of business value and ethical issues, apply theories on practical problems, and handle an assortment of tools. Drawing on the principles of Action Research cycle (Baskerville, 1999), as shown in Figure 2, the following steps were conducted:

Diagnosing: The course in BI was introductory with certain pedagogical challenges. Unlike Edgington's (2011) brand new course, our BI course had been taught twice before by the same lecturer. First, a number of terms and abbreviations were needed make a conceptual foundation. Second, the students may struggle to understand and differentiate the four steps of the process of BI (data - information - decision - action). Searching for new ways to make BI learning more fun, we reviewed the literature for possible approaches, resulting in our framework as described above.

Action Planning: Four puzzles, each of them illustrating key BI concepts from Figure 1, were constructed for the use in the class.

Action Taking: The four puzzles were introduced for the students in four consecutive teaching sessions. About 60 minutes were spent on each puzzle, except for puzzle three, where the students asked for an additional 30 minutes to complete the task. The students were observed as they solved the puzzles, for example, their questions and comments to the lecturer and to each other. Further details about the four puzzles are described in the next section.

Evaluation: Observation during the lecture was used to understand how the students solved the puzzles. In the fifth lecture, an anonymous survey was conducted with all students present to measure their perceived learning and satisfaction. The survey was distributed on paper to ensure 
anonymity, and the students were requested to be honest, but to the point, in their replies. The questionnaire is found in Appendix A. Questions included whether the puzzles were fun and/or useful for learning the BI objectives. The students were also informed that the aim was to produce research similar to Fang and Tuladhar's paper (2006), which they had previously read. Such an agreement "contributes to the internal validity of the research" (Davison, Martinsons, \& Kock, 2004, p. 69).

Specifying Learning: This stage is about reflecting on the outcomes so far. In addition to the quantitative data, the qualitative data analysis builds the approach as described by Miles and $\mathrm{Hu}-$ berman (1994). The outcomes of the actions were analyzed practically and theoretically, drawing on related literature. We scrutinized the four puzzles: how they were perceived by the students and the perceived differences between the puzzles.

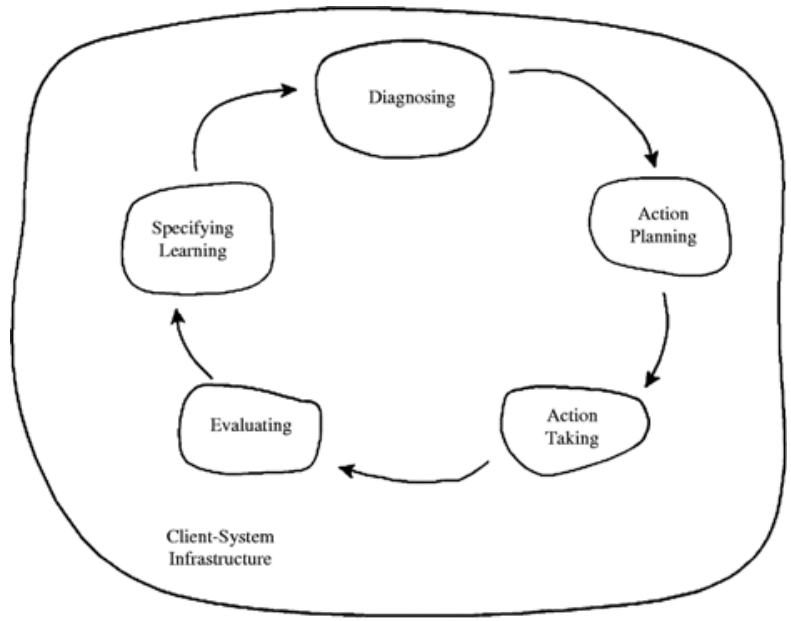

Figure 2: The action research cycle (Baskerville, 1999, p. 14)

The Four Puzzles

In this section we describe how the puzzles were presented, how the students attempted to solve them, and finally the results of the students' effort.

\section{Puzzle One: Rusty Meters in London}

The learning objective was to introduce the concept of data warehouse, defined above as a collection of data from several sources. The whole class solved the puzzle as one group. They had only one tool: making ad hoc queries to simulated databases residing in the head of the teacher.

Puzzle: The idea for this puzzle was taken from a paper describing how parking meters were mysteriously rusting in a confined area of London (Foss \& Bond, 2005). The problem was that the meters were rusting from within and only in a given borough. Replacing them was expensive for the community. How could this problem be solved?

Process: The students were told that they had access to all possible information on the city, and it was further explained to them that this meant querying the lecturer.

The students immediately started guessing, forgetting any strategy for solving the problem. Typical random guesses were, “The rusty meters are shorter, or made of different material!” They had to be reminded of making use of data, which could only be extracted from the lecturer. Slowly, 
the nature of questions changed. For example, they started to inquire about the income of the people living in the streets with rusty meters and received the answer: "They make less money."

Students: "Do we know where they shop?”

Lecturer: "Yes, in low-price stores."

Students: "What do they buy?”

Lecturer: "Many plastic items, for storing food. In all shapes and forms."

The lecturer (like any database) would not respond if the query was incorrect:

Students: "It has to be some kind of vandalism!"

Lecturer: "Your query does not return any data. Please rephrase your query."

Students: "OK. Do the rusty meters show sign of tampering when examined?"

Result: After about one hour one student suggested something with ice cubes. This was indeed the correct solution: the car owners in the streets with rusty meters made "ice coins" which would later melt inside the meter! The class also discussed how the authorities acted on this information.

\section{Puzzle Two: Dr. Snow's “Ghost Map” from 1854}

The next puzzle was placed in the context of "Business Intelligence anno 1854" and was also given to illustrate how people tend to make decisions not on information, but on previous experience or dogmas. In less than one year, from September 1848 to August 1849, there was a cholera epidemic in London taking 7466 lives (Snow, 1854, as cited in Water Institute, n.d.). The medical profession, authorities, and waterworks all agreed that cholera infects though "bad air". When a new outbreak of cholera started in August, 1854, Dr. Snow eventually suspected the bacteria to spread through water and went from door to door in Soho, collecting data on his "Ghost Map", (Johnson, 2006) shown in Figure 3.

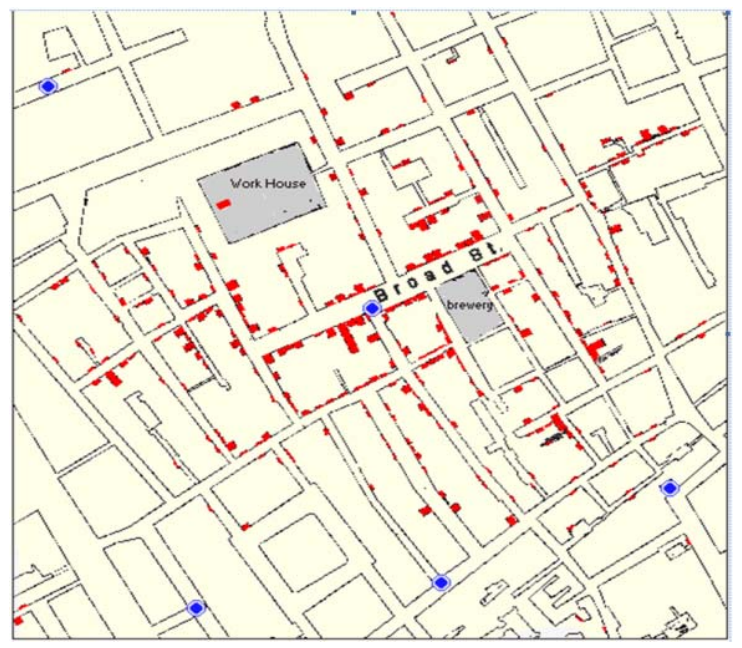

Figure 3: Dr. Snow's Ghost map (based on picture from http://www.theghostmap.com/)

Puzzle: The map (Figure 3) was shown to the students on a projector and given the question: "What does it show? Which kind of information can you make from this map?"

Process: Like in puzzle one, the students acted as one group and could only query the lecturer as omniscient. 
Lecturer: "Has anyone seen this map before?” (No student had seen it.) "Where is it?" (Someone soon guessed London.) "How old is the map?” (Someone suggested fifty years old, after 3-4 attempts: 1850’s.)

Knowing that the map was over one hundred years old, they quickly matched the blue dots ( $)$ with water supply (five in total in the map). Then they started their quest for the red dots (5). "Horses?” - but quickly landed on people. The students had clearly learned from puzzle one; the questions where now of the character: "Do the people work at the brewery? Is it the map of a land owner, visualizing tenants who are late with rent?"

Result: One student eventually connected the map with cholera outbursts. Having revealed that the map indeed indicated death by cholera, they immediately matched the death having to do with the one water pump with the numerous red dots drawn to it in "Broad Street".

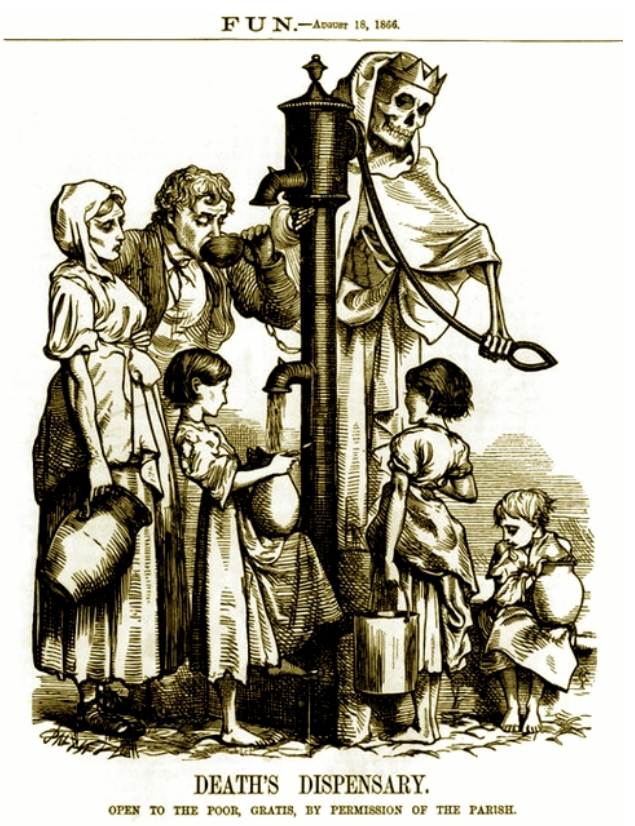

Figure 4: "Death's Dispensary" (Pinwell, 1866, as cited in Water Institute, n.d.)

Having turned data into information, “death is caused by water, not by air”, the students were challenged on "How to act based on this information?" The decision seemed obvious to the students, namely, "Close down that pump", but it took the British authorities a whole week to act correctly on the new information (Johnson, 2006), which is illustrated with small fonts under the drawing in Figure 4: "Open to the poor, gratis, by permission of the parish" (picture retrieved from Water Institute, n.d.). Johnson (2006) reminds us that cutting off the water supply for a whole street in Soho was not an easy decision for the authorities; however, for the first time, the fight against cholera “...would be challenged by reason, not superstition” (p. 163).

\section{Puzzle Three: Text Mining}

As presented in the literature review, web- and text mining are both increasingly popular (Edgington, 2011; Turban et al., 2011), which amongst others can make a foundation for sentiment analysis. During the ash crisis in spring 2010, the airline companies Norwegian and SAS used Facebook for communication with passengers (Presthus \& Bygstad, 2010).

Puzzle: Prior to the exercise, all words from Norwegian and SAS pages on Facebook had been extracted in an Excel file, counting 60,000 words. The students were asked to categorize the data 
into positive and negative words and to accumulate each category, in order to find out whether the sentiment, or mood, of the passengers was negative or positive.

Process: The class was divided into five groups. They were instructed to manually categorize the words and to use Excel for making graphs. At first the students were overwhelmed by the amount of words. The lecturer needed to motivate them by telling them that this task had been performed already and had taken less than two hours. Attention was also drawn to the fact that this was real data from real web sites.

Result: The students spent over one hour, even insisting on more time to complete the task. The result was five similar graphs from the students, of which one example is presented in Figure 5.

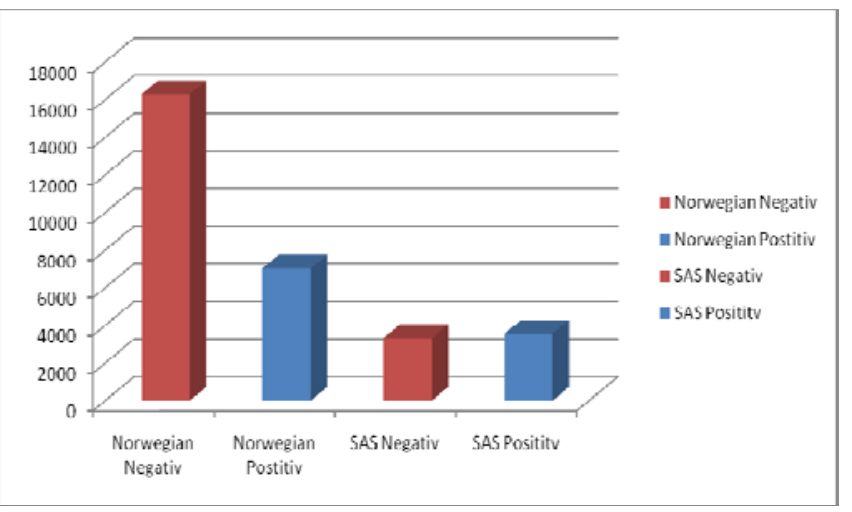

Figure 5: An example of graph by the students having completed puzzle three

All students reported the text analysis to be categorization, as we had a predefined set of categories: positive and negative words. They also correctly identified the mining as web content mining (as opposed to web usage or web structure mining).

\section{Puzzle Four: ETL/Data Mining}

The learning objective of the last puzzle was to understand the ETL (Extraction, Transformation, and Load) process and to conduct numerical data mining.

Telenor is the largest telecommunication operator in Norway. In addition to telephone and Internet services, Telenor also offers entertainment such as digital music files. In 2009, Alexander Rybak represented Norway and won the European Song Contest with his song "Fairytale", and Telenor offered selected customers a mobile subscription to purchase this song. Like puzzle three, the students were placed in groups and given two files with numeric data from Telenor's Sales and Marketing department. One file shows how many customers received an SMS on their mobile offering to purchase Rybak's single "Fairytale" (extracted from Marketing department). The other file shows how many customers actually purchased "Fairytale" regardless of having received an offer or not (extracted from Sales department).

Puzzle: The students were presented the following task: "The management at Telenor wants to know how effective the campaign was, meaning: How many who received an offer on their mobile, also purchased the single "Fairytale"?"

Process: The two files consisted of (modified) customer numbers. The one file, Offer, contained 100,000 numbers; the other, Sale, contained 5239. Moreover, the latter contained data in different format, as illustrated in Figure 6. Before the students could compare the data, they had to somehow remove the prefixes "1-”. Two customers had also purchased the song 4 times each. 


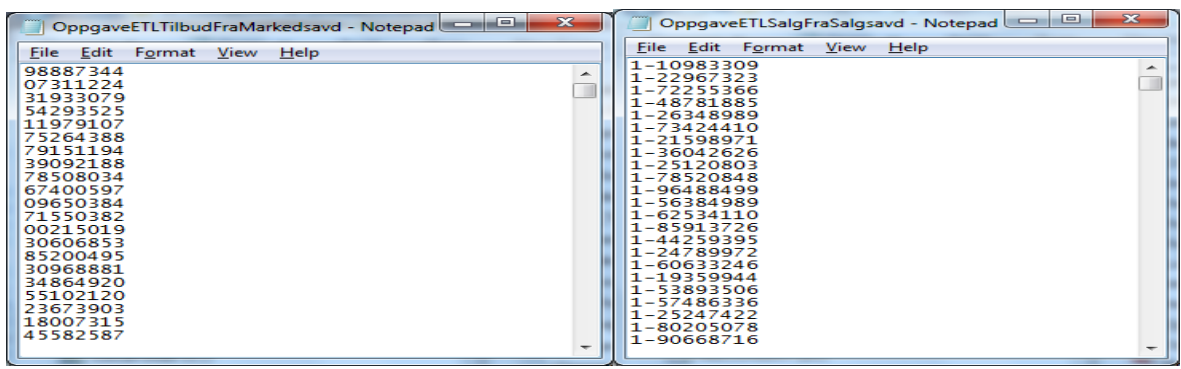

Figure 6: Two files, "extracted" from Marketing and Sales Department

Result: Three groups presented the correct answer (2666 customers). The rest managed to transform the data and compare the two source files but failed to identify the two customers having purchased four songs each. When confronted with the fact that their response was not quite correct, one student shrugged and replied, "How important can it be?"

All four puzzles were based on a real life situation, using real life data. A summary of the puzzles are found in Appendix B. The students solved all puzzles but the last, where the majority was close to finding the correct answer. The next section discusses our findings.

\section{Findings and Discussion}

We begin by returning to our research question: How can real life puzzles contribute to improved learning in $B I$ ? The puzzles were designed in order to combine fun and learning. Table 1 summarizes the students' replies to the question: "Was the puzzle fun?"

Table 1: Was the puzzle fun?

\begin{tabular}{|l|l|l|l|}
\hline Fun? $\rightarrow$ & Yes & Somewhat & No \\
\hline Puzzle 1 & 15 & 4 & 0 \\
\hline Puzzle 2 & 16 & 2 & 1 \\
\hline Puzzle 3 & 11 & 5 & 3 \\
\hline Puzzle 4 & 8 & 5 & 0 \\
\hline Sum & 50 & 16 & 4 \\
\hline
\end{tabular}

As Table 1 shows, $71 \%$ of the students found all of the puzzles to be fun. The most popular puzzles were number 1 and 2, while puzzles 3 and 4 were perceived somewhat less fun. We proceed with elaborating what made the puzzles exciting but also pedagogically successful. Table 2 summarizes the students' replies to the question: "Did the puzzle help you understand key concepts of BI?”

Table 2: Did the puzzle help you understand key concepts?

\begin{tabular}{|l|l|l|l|}
\hline Useful? $\rightarrow$ & Yes & Somewhat & No \\
\hline Puzzle 1 & 8 & 6 & 2 \\
\hline Puzzle 2 & 13 & 4 & 1 \\
\hline Puzzle 3 & 13 & 4 & 1 \\
\hline Puzzle 4 & 10 & 2 & 0 \\
\hline Sum & 44 & 16 & 4 \\
\hline
\end{tabular}

Table 2 illustrates that the majority (68\%) of students also found the puzzles to be useful in understanding the key concepts of BI (data warehouse, data-, text- and web mining, the process of BI and ETL). The totals of responses in Tables 1 and 2 differ because not all students attended every puzzle. 


\section{Real Life Problems: Intriguing and Dramatic}

We found that the students' enthusiasm was associated with interesting real life problems. As described in the previous section, the students asked many questions on the facts of the cases and generally engaged in the puzzles. We note, however, that the students were more engaged in the first three tasks. The students were very interested in the outcome of Dr. Snow's discovery but less in Telenor's campaign. The deaths of thousands of people in 19th century London was more intriguing than a relatively trivial business problem at a telecom company. In our survey, students typically reflect on puzzle two:

"Interesting to see how long the government took to accept Snow was correct"

"Fun task; as it is from real life"

Most research on how to teach engineering leans on constructed problems. Examples are murder mysteries (Highley \& Marianno, 2001) or river crossing (Michaelewicz \& Michaelewicz, 2007; Moursund, 2007). Moursund (2007) argues that it is up to the students to make the connection between the constructed examples and the real world. Our evidence points to another direction, and one reason may be that business students tend to perceive real world problems as more motivating than fabricated problems. Finally, we note that Mrdalj's (2007) data mining students reported that it was the real life problems which made the course interesting.

\section{Real Life Data: Genuine and Large Volume}

Our findings reveal that real life data was motivating. The volume of data was modest in the two first puzzles, while quite substantial in three and four. Working with real life data challenged the students' creative and analytical abilities and made them very curious to find the answer. Two typical student comments were:

"Challenged creativity and logical thinking”

"Jumpstarted thoughts and became curious of the reason"

One might wonder how much data is needed to conduct an interesting analysis. Mrdalj's students liked real life data, but wanted a larger amount (Mrdalj, 2007). Our experience is that the volume of data in itself is not crucial for how interesting the students find the exercise. Rather, it is the patterns of the analyzed data which contribute to solve the real world problem. Both puzzles two and three were perceived as nearly equally fun, although the amounts of data were very different.

A key feature is that Business Intelligence is based on certain logic in querying; you cannot ask directly for the solution, but you have to frame your questions following certain techniques related to the available data. It is the pattern of the data that will reveal the solution. These patterns may be surprising: a map with streets and dots actually lead to a new discovery on how cholera spreads.

There are also challenges with real world data. One challenge is that it puts a lot of pressure on the lecturer in order to supply these data, and the other is ethical issues associated with privacy, business property, and secrecy. We will return to these issues.

\section{Real Life Solutions: One Solution, Known to Exist}

Having been presented the puzzle, the students were quick to ask whether the answer existed. We find that the students should be told in advance that there is indeed one correct solution to the problem and that the answer can be derived only from the data. Moreover, the solution needs to be intuitive and have an impact on business value. Three students commented:

"It made us understand how to reach a solution by analyzing a database" 
"Fun to reach answer, it was not obvious"

"Very good to learn how this information can be used to make money"

In contrast, the Telenor case was less motivating; even though the students knew there was one correct answer (2666 customers), some students failed parts of the ETL process and landed on 2672. When confronted that this was incorrect, some students replied, “Isn't it close enough”? Perhaps the puzzle would be more motivating had the consequences of the solution been more radical, such as giving a large bonus or gift to the detected customers. This was not the case at Telenor and may be one drawback of using real life puzzles: real life consists of many mundane cases and situations.

Previous research has shown that there must be rules in order to solve the puzzle (Highley \& Marianno, 2001). In our case, the students were not allowed to search the Internet, and they were informed about these rules in advance. None of the students broke any rules. Although Michalewicz and Michalewicz (2007) warn that it may take some time to reach the solution, we still believe that the solution should not be fabricated when using real life data. Moreover, the solution must be perfectly logical, based on the evidence. Having spent quite some time finding the correct answer, the students are not motivated for another fifteen minutes for the answer to be explained.

\section{Fun and Learning}

The findings in Tables 1 and 2 might indicate that there is a close relationship between fun and learning. We do not propose such a general relationship, as we think this is a quite complex issue. We do, however, briefly draw attention to these questions: Can there be too many puzzles in the teaching? Is there a risk that the students become passive and expect the learning to be wrapped in entertainment? A few students complained about too many "parlor games" and, according to the survey, they found the two last puzzles took too long:

"Spent too much time, we would have got the idea with less words"

"Overall, too much time spent. Less interesting whether fun, should focus on useful"

This may indicate that the students see the brainteasers for what they are meant to be, namely, a tool for learning BI concepts and processes. Real life puzzles do not replace the traditional classroom teaching but are meant as a complement to reading, reflecting, and lab work.

\section{Summing Up: What Make Real Life Puzzles Work?}

Overall, we argue that real life puzzles are a powerful approach to learn BI. Real life problems are conceived by the students as interesting and motivating. Real life data also create a rich and abundant source for problem solving using BI techniques. Real life solutions represent an exciting target for the students to reach, with a strong feeling of satisfaction when the solution is found. Moreover, the real life approach teaches the students to think out-of-the-box. This is illustrated with a number of characteristic comments from the students:

"Very fun way to make us think differently"

"I would probably be clueless without this puzzle"

What make real life puzzles work? In addition to being perceived as fun and motivating, we believe that there exists an underlying explanation for the positive outcome. The BI process is characterized by a certain structure: you have a question and there exists a large amount of data that may contribute to your solution. However, the answer can only be found by querying in a certain way, that is, you have to relate strictly to the structure of the available data. 
The puzzle approach imitates this process. You start with a question or problem, with a description of the structure of the available data. If the students pose questions that do not relate directly to the data structure, the question will be rejected. (Recall that this was the case in puzzle one, where a student tried to ask about vandalism.) This teaches the students to formulate the questions based on the data structure.

We argue that the similarities between the BI process and the puzzle process prepare the students for Business Intelligence learning in an indirect way. Through the gradual realization on how these puzzles work, the students are able to connect the logical structures of puzzles with the logical way of BI queries.

There are however limitations and challenges to our research, which are briefly assessed in the next section.

\section{Limitations}

First, we have to acknowledge that this was a small study, consisting of a one semester course. Although we build on the students' own perceptions of their learning, our findings are nonetheless consistent with research described in the literature review (Wixom \& Ariyachandra, 2011).

Second, previous research (Mrdalj, 2007) has emphasized that it is time consuming and difficult to identify such real life puzzles. Puzzles such as Rusty Meters and Ghost Map may only be used once for each cohort - even provided that no student has heard of it before somehow. The BI lecturer faces the risk of running out of puzzles from the real world. At the moment, there is no "World Puzzle Bank" although it should be possible to draw on other people's puzzles and cases, for example from Teradata University Network (Teradata, 2012).

Third, while today's BI techniques can extract large amounts of real life data from multiple sources such as Facebook and other web pages, ethical concerns may prevent use of real life data. For example, it would not be good practice to apply peoples’ personal data extracted from real registers.

\section{Conclusion}

In response to Wixom and Ariyachandra's (2011) call for a more relevant and practical schooling of BI, we have investigated how to teach some of the core concepts and practices of Business Intelligence at a university college, while at the same time making learning fun. The students were given four tasks covering learning outcomes of data warehouse, BI and ETL process, data- and text mining, as well as reflecting on the business value and advantages of a completed BI process.

Our conclusion is that real life puzzles are a powerful method to teach BI. Both puzzles and BI address solving a problem, with no obvious answer, using certain steps. Real life problems are interesting for the students, real life data create a rich source for problem solving using BI, and real life solutions provide a strong feeling of satisfaction when the answer is obtained.

We argue that the puzzle approach works because it imitates the BI process. You start with a question or problem and a description of the structure of the available data. If the students pose questions that do not relate directly to the data structure, the query will be rejected. This teaches the students to formulate the questions based on the data structure, which is essential for understanding the BI concepts and process.

There are also limitations to using real life puzzles for teaching BI. Puzzles do not replace the traditional classroom teaching, but serve as a complement. Preparing puzzles represents a challenge for the lecturer, such as collecting large amounts of data and addressing ethical issues. Finally, some puzzles may only be used once for each audience. 
Further research on Puzzle-Based Learning can be conducted in subjects other than BI. For example, one might investigate in more depth the relationship between fun and learning. Within the BI field, related venues of research could be examined. Further research could investigate the mental process of Puzzle-Based Learning in relation to the specific challenges found in BI education. Such research might aim for a more causal explanation, for example, the direct effects of puzzles on student's grades.

\section{References}

Baskerville, R. (1999). Investigating information systems with action research. Communications of the Association for Information Systems, 19 (Article 2).

Connolly, T., \& Begg, C. (2010). Database systems. A practical approach to design, implementation, and management. Addision Wesley.

Davenport, T. H. (2010). Business intelligence and organizational decisions. International Journal of Business Intelligence Research, 1(1), 1-12.

Davenport, T. H., Harris, J. G., De Long, D. W., \& Jacobsen, A. L. (2001). Data to knowledge to results: Building an analytic capability. California Management Review, 43(2), 117-138.

Davison, R. M., Martinsons, M. G., \& Kock, N. (2004). Principles of canonical action research. Information Systems Journal, 14, 65-86.

Edgington, T. M. (2011). Introducing text analytics as a graduate business school course. Journal of Information Technology Education: Innovations in Practice, 10, 207-234. Retrieved from http://www.jite.org/documents/Vol10/JITEv10IIPp207-234Edgington922.pdf

Fang, R., \& Tuladhar, S. (2006). Teaching data warehousing and data mining in a graduate program of information technology. Consortium for Computing Sciences in Colleges, Journal of Computing Sciences in Colleges, 5, 137-144.

Foss, B., \& Bond, A. (2005). Privacy, risk and good and bad consumers. Database Marketing \& Customer Strategy Management, 13(1), 10-23.

Highley, K. A., \& Marianno, C. M. (2001). Making engineering education fun. Journal of Engineering Education, January 2001, 105-107.

Howson, C. (2008). Successful business intelligence. Secrets to making BI a killer app. The McGraw-Hill Companies.

Johnson, S. (2006). The ghost map. Penguin Books.

Li, H. (2005). Applications of data warehousing and data mining in the retail industry. IEEE Xplore, 10471050.

Luhn, H. P. (1958). A business intelligence system. IBM Journal of Research and Development, 2(4), 314319.

Michaelewicz, Z., \& Michaelewicz, M. (2007). Puzzle-based learning. Proceedings of the 2007 AaeE Conference, Melbourne, pp. 1-8.

Miles, M. B., \& Huberman, A. M. (1994). Qualitative data analysis. Thousand Oaks: Sage Publications.

Moursund, D. G. (2007). Introduction to using games in education: A guide for teachers and parent0.s Available free online. Retrieved November 11, 2010, from http://uoregon.edu/ moursund/Books/Games/games.html

Mrdalj, S. (2007). Teaching an applied business intelligence course. Issues in Information Systems, VIII(1), 134-138.

Mrdalj, S. (2011). Would cloud computing revolutionize teaching business intelligence courses? Issues in Informing Science and Information Technology, 8, 209-217 
Norton, L. S. (2009). Action research in teaching and learning: A practical guide to conducting pedagogical research in universities. Routledge.

Overby, E., Bharadwaj, A., \& Sambamurthy, V. (2006). Enterprise agility and the enabling role of information technology. European Journal of Information Systems, 15, 120-131.

Presthus, W., \& Bygstad, B. (2010). Facebook as agile CRM? A business intelligence analysis of the airline ash crisis. NOKOBIT, Gjøvik. Tapir Akademisk Forlag.

Power, D. J. (2007). A brief history of decision support systems. DSSResources.COM, World Wide Web, version 4.0, March 10, 2007. Retrieved February 16, 2012 from http://DSSResources.COM/history/dsshistory.html

Reason, P., \& Bradbury, H. (2007). The SAGE handbook of action research: Participative inquiry and practice. Sage.

Savery, J. R. (2006). Overview of problem-based learning: Definitions and distinctions. The Interdisciplinary Journal of Problem-based Learning, 1(1), 9-20.

Teradata. (2012). Teradata University Network. Retrieved February 16, 2012, from http://www.teradatauniversitynetwork.com/tun/

Turban, E., Aronson, J. E., Liang, T.-P., \& Sharda, R. (2007). Decision support and business intelligence systems. Pearson Prentice-Hall.

Turban, E., Sharda, R., \& Delen, D. (2011). Decision support and business intelligence systems. Prentice Hall.

Water Institute. (n.d.). Water Institute. Retrieved February 27, 2012, from http://water-institute.eu/

Wixom, B. H., \& Ariyachandra, T. (2011). State of business intelligence in academia 2010. Presented at BI Congress II.

Wixom, B. H., Ariyachandra, T., Goul, M., Gray, P., Kulkarni, U., \& Phillips-Wren, G. (2011). The current state of business intelligence in academia. Communications of the Association for Information Systems, 29, Article 16. Available at: http://aisel.aisnet.org/cais/vol29/iss1/16 


\section{Appendix A}

(The questionnaire was given in lecture number 5. It was anonymous.)

The class has been given 4 exercises. Please circle the ones you have been attending:

(1) Rusty meters in London

(2) Dr. Snow's ghost map (cholera)

(3) Text mining data from Facebook (sentiment analysis)

(4) ETL/Data mining data from Telenor's Sales and Marketing department (effect of campaign)

For each exercise you have been attending, please answer:

(1) Rusty meters

Was it fun to solve this exercise? (Please circle) Yes Somewhat No

Please describe

Did it help you to understand the key concept of Business Intelligence?

(2) Dr. Snow's ghost map (cholera)

Was it fun to solve this exercise? (Please circle) Yes Somewhat No

Please describe

Did it help you to understand the key concept of Business Intelligence?

(3) Text mining data from Facebook (sentiment analysis)

Was it fun to solve this exercise? (Please circle) Yes Somewhat No

Please describe.

Did it help you to understand the key concept of Business Intelligence?

(4) ETL/Data mining numeric data from Sales and Marketing department at Telenor.

Was it fun to solve this exercise? (Please circle) Yes Somewhat No

Please describe

Did it help you to understand the key concept of Business Intelligence?

Any comments?

\section{Appendix B}

The table below summarizes the four puzzles.

\begin{tabular}{|l|l|l|l|}
\hline Puzzle & Key BI concept & Learning objective & Outcome by students \\
\hline Rusty meters & Data warehouse & $\begin{array}{l}\text { Collecting data from several } \\
\text { sources to solve a problem }\end{array}$ & $\begin{array}{l}\text { Found the answer within } \\
\text { one hour }\end{array}$ \\
\hline $\begin{array}{l}\text { Dr Snow's Ghost } \\
\text { Map }\end{array}$ & $\begin{array}{l}\text { Data mining, the } \\
\text { BI process }\end{array}$ & $\begin{array}{l}\text { Map can be data source. Im- } \\
\text { portance of acting upon infor- } \\
\text { mation }\end{array}$ & $\begin{array}{l}\text { Found the answer within } \\
\text { one hour }\end{array}$ \\
\hline $\begin{array}{l}\text { Norwegian and } \\
\text { SAS on Facebook }\end{array}$ & $\begin{array}{l}\text { Text-, web min- } \\
\text { ing }\end{array}$ & Sentiment analysis & $\begin{array}{l}\text { All groups reached simi- } \\
\text { lar results }\end{array}$ \\
\hline $\begin{array}{l}\text { Effect of campaign } \\
\text { at Telenor }\end{array}$ & ETL process & $\begin{array}{l}\text { Data sources often have differ- } \\
\text { ent formats }\end{array}$ & $\begin{array}{l}\text { Only three groups reached } \\
\text { the correct answer }\end{array}$ \\
\hline
\end{tabular}




\section{Acknowledgements}

First, the authors would like to thank the E-business class of 2010 at the Norwegian School of IT for solving puzzles and providing reflections in the survey afterwards. Additional gratitude goes to Knut Urbye for comments. This article builds on a UKAIS conference paper presented in Cambridge, April 2011, and the authors are thankful to the anonymous reviewers from this conference. Finally, special appreciation goes to Grandon Gill and the anonymous reviewers of Journal of Information Technology Education: Innovations in Practice for raising the quality of this article.

\section{Biographies}

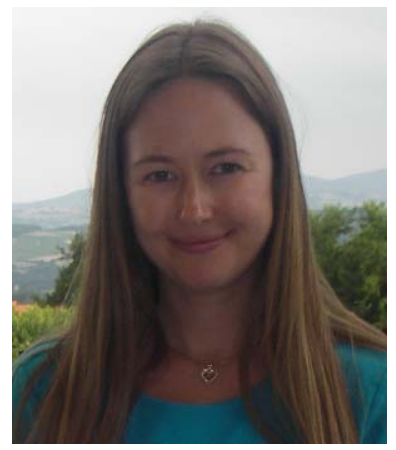

Wanda Presthus holds a Master of Technology from Brunel University. She is employed as an assistant professor at the Norwegian School of Information Technology, where she is director for the E-business program. She is currently pursuing a $\mathrm{PhD}$ at the IT University of Gothenburg, in the field of Business Intelligence. Her research interests include the Business Intelligence process and tools, business systems, as well as web- and text mining.

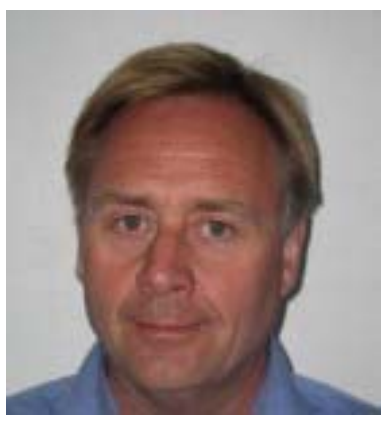

Bendik Bygstad holds a PhD in computer science and a Master of Sociology. He worked 15 years in the IT industry. He is currently a professor at the Norwegian School of Information Technology. His main research interest is IT-based innovation and IS research methods. He has published articles in such journal as Information Systems Journal, Journal of Information Technology, International Journal of Project Management and International Journal of Technology and Human Interaction. 